\title{
UNCLARITIES ABOUT ARTICAINE: EFFICACY AND THE RISK OF PARESTHESIA
}

\author{
Nicolas de Ridder ${ }^{1 a}$, Constantinus Politis ${ }^{1 b^{*}}$ (D) \\ 'Department of Oral and Maxillo-Facial Surgery, Faculty of Medicine, Catholic University of Leuven, Leuven, Belgium \\ aMD, Student in Master of Medicine; ${ }^{b} \mathrm{MD}, \mathrm{DDS}, \mathrm{MM}, \mathrm{MHM}, \mathrm{PhD}$, Professor and Head
}

ABSTRACT DOI: https://doi.org/10.25241/stomaeduj.2020.7(1).art.6

Background: Articaine is a very popular local anesthetic in dentistry. A lot of claims have been made about articaine over the years, both positive and negative. Many clinicians claim articaine is superior to lidocaine. However, since a study in 1995 claiming an increased risk of paresthesia, there has been debate about whether this is true or not.

Objective: To review the current literature to clarify the current ambiguities about the possible superior efficacy and the alleged higher risk of paresthesia.

Data sources: As a basis, a handbook on local anesthesia was read, as well as its references to the topics of interest. Afterward, the literature was searched for publications about both the efficacy and the risk of paresthesia from 1990 to 2019.

Study selection: Articles about the efficacy with clear data and minimal risk of bias were selected. For paresthesia, the original articles were selected as well as more recent reviews highlighting the flaws in the first studies.

Data extraction: Information about the efficacy and the possible superiority of articaine compared to lidocaine was extracted. For paresthesia, the most important historical publications were reviewed and more recent reviews were

OOPEN ACCESS This is an Open Access article
under the CC BY-NC 4.0 license.
Citation: de Ridder N, Politis C. Unclarities about articaine:
efficacy and the risk of paresthesia.
Stoma Edu J. 2020;7(1):44-51.
Received: January 22, 2020
Revised: February 13, 2019
Accepted: February 20, 2020
Published: February 22, 2020
Corresponding author:
Professor Constantinus Politis, MD, DDS, MM, MHM, PhD,
Head, Department of Oral and Maxillo-Facial Surgery,
Faculty of Medicine, Catholic University of Leuven,
Kapucijnenvoer 33, BE-3000 Leuven, Belgium
Tel: / Fax: 0032 (0)16332462,
e-mail: constantinus.politis@uzleuven.be
Copyright: $\odot$ 2020 the Editorial Council
for the Stomatology Edu Journal.
evaluated.

Data synthesis: These data were synthesized in an overview consisting of two parts. First, the properties of articaine were review and what was learned about the efficacy of articaine in relation to other local anesthetics was discussed. Secondly, an overview of the history of paresthesia was given and the flaws and unclarities were highlighted.

KEYWORDS

Articaine; Epinephrine; Efficacy; Paresthesia; Dentistry.

\section{INTRODUCTION}

Articaine is an amide dental local anesthetic, synthesized in 1969 in Germany.

It was specifically developed for dental use and got its approval for clinical use in countries all over the world in the years to follow. It became increasingly popular and is now the second most used local anesthetic in dentistry.

Annually, approximately $600,000,000$ cartridges are manufactured [1]. In 2018 the market share of articaine was $39,3 \%$ in the United States, and as much as $97 \%$ in Germany $[1,2]$.

However, lidocaine still remains the golden standard for local anesthesia.

Over the years, articaine has been the subject of intense discussion and (anecdotal) claims (both good and bad). Some of the good claims include a supposedly better potency, faster onset of anesthesia and a higher success rate.
The bad claim is mainly an alleged increased risk of paresthesia. Some of these claims have been shown to be correct (like the success in buccal infiltration anesthesia in the adult mandible).

However, on a lot of other claims or initial reports there is no scientific evidence to prove them or the results are contradictory.

\section{MATERIALS AND METHODS}

As background information and the basis of this review, Malamed's Handbook of Local Anesthesia (seventh edition) was read.

Afterward, searches were made on PubMed, Trip database and Limo with different combinations of the following keywords: safety, clinical characteristics, paresthesia, efficacy, lidocaine, articaine, local anesthetics, epinephrine. A selection was made of the most relevant articles to make this narrative review. 


\section{CLINICAL CHARACTERISTICS}

Articaine hydrochloride (or4-methyl-3-[2-(propylamino) propionamido]-2-hiophenecarboxylic acid methyl ester) is used in dental cartridges of $1.8 \mathrm{~mL}$. These cartridges contain $72 \mathrm{mg}$ of articaine and 0.09 to 0.18 $\mathrm{mg}$ of epinephrine, depending on the concentration (1:200,000 and 1:100,000 respectively) [1].

\subsection{Articaine}

Although it is classified as an amide anesthetic, articaine is considered a unique entity within the amide local anesthetics. It has different properties compared to the other local anesthetics. Most importantly, it contains an ester-linkage that can be hydrolyzed by plasma-esterases and turns articaine in an inactive compound: articainic acid [2]. This rapid manner of inactivation is the same biotransformation that occurs in the elimination of ester anesthetics [1]. This contributes greatly to the low systemic toxicity of the drug. This mechanism also gives articaine its relatively short elimination half-life of only 27 minutes (compared to 90 minutes for lidocaine) [2]. Secondly, it contains an aromatic thiophene ring which would ensure greater lipid solubility. This would increase potency because articaine is better in penetrating tissue and bone [3]. Finally, articaine has a high degree of protein binding (95\%). This high degree of protein binding may account for a longer duration of anesthetic effect as well for the increased tendency to bind to the protein receptor [1].

Clinically, the drug works by binding reversibly to the alfa-unit of the voltage-gated sodium channels in the nerve, thereby preventing the propagation of action potentials [3]. This gives pulpal anesthesia for approximately 60 minutes and soft tissue anesthesia for 3 to 5 hours, making articaine an intermediate-acting anesthetic [4]. There is a theory suggesting that local saturation of serum esterases would cause a delay in local metabolism of articaine. This mechanism would account for the prolonged anesthetic effect while the systemic toxicity remains low [4]. A study showing high alveolar blood levels of articaine post-extraction with an increased metabolic rate from articaine to articainic acid supports these claims [5]. As with all drugs, the clinician should be careful not to elicit overdose reactions by using too much of the drug. Articaine has a maximum recommended dose of $7.0 \mathrm{mg} /$ $\mathrm{kg}$ [1]. A cartridge contains $1.8 \mathrm{~mL}$ of anesthetic solution, so for articaine $4 \%$ it equals $72 \mathrm{mg}$ of articaine. A normal healthy adult of $72 \mathrm{~kg}$ would have a maximum recommended dose of $504 \mathrm{mg}$. This equals 7 cartridges. These maximum dosages are well above the dosages normally needed in routine dental care (normally a maximum of about three to four cartridges are needed during routine dental care). With six cartridges you could achieve anesthesia of a full adult mouth [1]. Nevertheless, exceeding the maximum recommended dose is the most frequent cause of overdose reactions in dental patients [1]. That is why it is important to always calculate this maximum dosage. If used within this range, articaine is a safe drug to use. However, in some cases (like certain cardiac patients) a dose restriction could be advisable to maximize safety, as discussed in another review. There are also other important things to remember to safely use dental local anesthetics and prevent overdose reactions. Basic injection techniques should be applied when administering local anesthetics to minimize the chance of an overdose reaction. Careful aspiration should be performed prior to every injection to avoid accidental intravascular injection [1]. Furthermore, one of the most important factors for overdose appears to be the rate of injection: ideally a cartridge is administered over a period of more than 60 seconds. A rapid injection (less than 15 seconds) results in significantly elevated blood levels when accidentally administered intravenously, facilitating an overdose reaction [1].

\subsection{Epinephrine}

Epinephrine is added to the anesthetic solution as a vasoconstrictor. This has several benefits: First of all, it elicits vasoconstriction in the blood vessels, which does not only delay the absorption of the local anesthetic and thereby decreasing systemic toxicity, but it also gives hemostasis, less per operative blood loss and better visibility. Secondly, it increases the depth as well as the duration of action of anesthesia, prolonging and enhancing the anesthetic effect. Because of this, the dose of anesthetic used can be reduced [1].

The addition of epinephrine does have its implications: because of its effects on the myocardium and the vascular tone, a dose restriction to a maximum of $40 \mu \mathrm{g}$ per appointment as stated by Bennett and Malamed $[2,6]$. This equals four cartridges of epinephrine 1:200,000. The safe use of $\leq 4$ cartridges of the higher concentrated anesthetic lidocaine (1:100,000 epinephrine) was recently confirmed in a systematic review [7]. A lot of the other contra-indications or possible interactions in the package leaflet of articaine are included because of the addition of epinephrine as well. It should be noted however that the doses of epinephrine used in dentistry are minimal.

One $1.8 \mathrm{~mL}$ of 1:100,000 and 1:200,000 epinephrine contains 0.018 and $0.009 \mathrm{mg}$ respectively. This dose is rather low compared to other uses of epinephrine in medicine $(0.3$ to $1 \mathrm{mg}$ in case of anaphylactic shock) [1]. In these small quantities, the systemic cardiovascular effects are modest to negligible depending on the type of patient [1]. Of course, it should be mentioned that in some cases it is not safe to use articaine (like some refractory unstable heart 
ITable 1. Successful pulpal anesthesia.

\begin{tabular}{|c|c|c|c|}
\hline & Articaine & Lidocaine & P-value \\
\hline $\begin{array}{c}\text { Mandibular } \\
\text { second molar }\end{array}$ & $75 \%$ & $45 \%$ & 0.0001 \\
\hline $\begin{array}{c}\text { Mandibular first } \\
\text { molar }\end{array}$ & $87 \%$ & $57 \%$ & 0.0001 \\
\hline $\begin{array}{c}\text { Mandibular } \\
\text { second premolar }\end{array}$ & $92 \%$ & $67 \%$ & 0.0001 \\
\hline $\begin{array}{c}\text { Mandibular first } \\
\text { premolar }\end{array}$ & $86 \%$ & $61 \%$ & 0.0001 \\
\hline
\end{tabular}

Robertson D, Nusstein J, Reader A, Beck M, McCartney M. The anesthetic efficacy of articaine in buccal infiltration of mandibular posterior teeth. J Am Dent Assoc. 2007;138:1104-1112, Table 1

diseases) [1]. However, these are all contraindications to general elective dental care as well and need immediate attention from a medical specialist.

\section{EFFICACY}

There are some reports of clinicians who state that 'in their opinion' articaine has a faster onset following injection. However, in a study comparing the time of onset of pulpal anesthesia after an inferior alveolar nerve block (IANB) between $2 \%$ lidocaine and $4 \%$ articaine in 1554 patients, these claims were not supported [2].

It has also been claimed that articaine may provide palatal anesthesia when given as maxillary buccal infiltration [1]. Although this claim is anecdotal, it could be attributed to the greater lipid solubility.

\subsection{Mandibular infiltration}

A claim that has been shown to be true is the significant success of articaine used by buccal infiltration in the mandible.

When articaine was used for mandibular infiltration in adults, it has been proven that the chances of success are significantly greater in comparison to lidocaine (see Table 1) [8].

The time of onset for pulpal anesthesia was also significantly shorter for articaine in the first and second molar, and the first premolar (see Table 2) [8]. Another study found similar results concerning the mandibular incisor: Both the duration and the success rate of pulpal anesthesia was considerably longer with the articaine solution [9].

The reason for this increased success rate could be the relatively thin cortical plate, subject to the potent penetrating capability of articaine [2].

Kanaa et al. did research on the addition of articaine or lidocaine infiltration to improve the success rate of anesthesia following an IANB [10].

As is turns out, articaine gives the best improvement in success rate comparing to lidocaine $(55,6 \%$ to $91,7 \%$ for the first molar, $66,7 \%$ to $88,9 \%$ for the second molar) [10].
ITable 2. Onset time of pulpal anesthesia.

\begin{tabular}{|c|c|c|c|}
\hline & $\begin{array}{c}\text { Articaine } \\
\text { onset } \pm \text { SD } \\
\text { (min) }\end{array}$ & $\begin{array}{c}\text { Lidocaine } \\
\text { onset } \pm \text { SD } \\
\text { (min) }\end{array}$ & P-value \\
\hline $\begin{array}{c}\text { Mandibular } \\
\text { second } \\
\text { molar }\end{array}$ & $4.6 \pm 4.0$ & $11.1 \pm 9.50$ & 0.0001 \\
\hline $\begin{array}{c}\text { Mandibular } \\
\text { first molar }\end{array}$ & $4.2 \pm 3.1$ & $7.7 \pm 4.3$ & 0.0002 \\
\hline $\begin{array}{c}\text { Mandibular } \\
\text { second } \\
\text { premolar }\end{array}$ & $4.3 \pm 2.3$ & $6.9 \pm 6.6$ & 0.0014 \\
\hline $\begin{array}{c}\text { Mandibular } \\
\text { first } \\
\text { premolar }\end{array}$ & $4.7 \pm 2.4$ & $6.3 \pm 3.1$ & 0.0137 \\
\hline
\end{tabular}

Robertson D, Nusstein J, Reader A, Beck M, McCartney M. The anesthetic efficacy of articaine in buccal infiltration of mandibular posterior teeth. $J$ Am Dent Assoc. 2007;138:1104-1112, Table 2

\subsection{Conclusion}

A meta-analysis by Katyal in 2010 comparing articaine with lidocaine concluded that articaine has a higher anesthetic success in the posterior first molar area, while the safety is comparable with lidocaine (RR $1.31,95 \% \mathrm{Cl}$ of 1.12 to 1.54 ) [11]. However, the variability of anesthetic success of certain techniques and the effect of local inflammation were not taken into account $[4,11]$. Yapp provided a comprehensive overview of seventeen papers comparing the efficacy of articaine [4]. Ten papers found no significant difference, while 7 papers did find an advantage for articaine (however each review investigated different clinical situations) [4]. As a conclusion, the overall efficacy of articaine is similar to lidocaine. For mandibular infiltrations, mental nerve blocks and a buccal infiltration following an IANB, articaine does appear to have a significant advantage [4]. Paxton and Thome reviewed all 27 publications until 2010 reporting on the efficacy of articaine [12]. These publications showed a variability of outcomes, but nevertheless their meta-analysis did show a significant difference $(9.21 \%$ higher proportion of success, $95 \% \mathrm{Cl} 2.56 \%$ to $15.58 \%$ ) [2]. This suggested an advantage for articaine, at least in some clinical situations [13]. Furthermore, articaine was compared with 1:100,000 and 1:200,000 epinephrine concentrations and no significant difference was found [12]. However, it should be noted that all these studies are only low to moderate-quality evidence so conclusions must be critically reviewed.

\section{PARESTHESIA}

Local anesthetics are used to achieve anesthesia in the desired area to perform a pain-free procedure. Normally this anesthesia wears off in a matter of hours, but there have been reports of paresthesia after local anesthetic use.

This paresthesia is a neuropathy that can manifest itself as a loss of sensation (anesthesia), burning/ tingling sensation (dysesthesia) or pain (allodynia, hyperesthesia) [2]. 
ITable 3. Risk of paresthesia from local anesthetic drugs.

\begin{tabular}{|c|c|c|c|}
\hline & 2007 & 2012 & Result \\
\hline Lidocaine & 0.64 & 0.5 & $\begin{array}{l}<1.0, \text { less than } \\
\text { expected }\end{array}$ \\
\hline Articaine & 1.19 & 0.97 & $\sim 1$, expected \\
\hline Mepivacaine & NA & 2.2 & $\begin{array}{l}>1.5 \text {, higher than } \\
\text { expected }\end{array}$ \\
\hline Prilocaine & 4.96 & 3.25 & $\begin{array}{l}>3.0 \text {, higher than } \\
\text { expected }\end{array}$ \\
\hline
\end{tabular}

The ratio derived from the percentage of reported cases of paresthesia divided the percent market share of the drug.

Malamed SF. Articaine 30years later. Oral Health. 2016; Table9

There have been studies reporting a higher incidence of paresthesia with the use of $4 \%$ local anesthetics like prilocaine and articaine. An overview of the history of this controversy is given below.

\subsection{History}

Everything started with a retrospective study by Haas and Lennon in 1995 [13]. They examined voluntary submissions that dentists made to their insurance agency. They found 143 cases of paresthesia over a 20-year period (1973 to 1993), excluding those associated with surgery [13].The paresthesia involved the lingual nerve, the inferior alveolar nerve or a combination of both [13]. Based on the distribution of the market share of local anesthetics in Ontario in 1993, articaine and prilocaine had a relatively higher risk of developing paresthesia [13]. In 1993, 10 of the 14 reports of paresthesia were related to articaine, the other 4 to prilocaine. This equals an overall risk of 1:785,000. The individual rates reported for articaine $(1: 588,235)$ and prilocaine $(1: 440,529)$ were a lot higher than the other anesthetics $(1: 1,250,000)$ [13]. Almost all of the forthcoming papers claiming an increased risk of paresthesia refer to this paper as the original source. Hillerup and Jensen conducted a study (2006) reviewing insurance claims in Denmark, where articaine was introduced in 2001 [14]. They claimed that articaine had a higher tendency to cause paresthesia as it was most reported to the Danish Medicines Agency by dentists [14]. They declared that articaine should not be the anesthetic of choice when administering an IANB until factual information is available, a statement consequentially recommended by the Danish Dental Association as well [14]. In this review, $77 \%$ of the cases reviewed involved only the lingual nerve, and not the inferior alveolar nerve [14]. In response, the Pharmacovigilance Working Committee of the European Union reviewed articaine use in 57 different countries addressing the controversy about paresthesia [15]. They estimated the number of patients receiving articaine is around 100 million annually [15]. In October 2006 they published the following report: "This investigation is a follow-up to an inquiry initiated in 2005. This enquiry resulted from suspicions that were raised
Table 4. Relative risks of paresthesia in Ontario, Canada and the United States.

\begin{tabular}{|c|c|c|}
\hline & Ontario, Canada & United States \\
\hline Mepivacaine & $1: 1,250,000$ & $1: 623,112,900$ \\
\hline Lidocaine & $1: 1,125,000$ & $1: 181,076,673$ \\
\hline Bupivacaine & NA & $1: 123,286,050$ \\
\hline Overall risk & $1: 785,000$ & $1: 13,800,970$ \\
\hline Articaine & $1: 440,000$ & $1: 4,159,848$ \\
\hline Prilocaine & $1: 588,000$ & $1: 2,070,678$ \\
\hline
\end{tabular}

Malamed SF.Articaine 30 years later. Oral Health. 2016; Table 8

in Denmark, that a local anesthetic, articaine, was responsible for an increased risk of nerve injuries compared with the risk associated with other local anesthetics (mepivacaine, prilocaine, lidocaine)" [15]. The report concluded: "Regarding articaine, the conclusion is that [the] safety profile of the drug has not significantly evolved since its initial launch (1999 in Denmark). Thus, no medical evidence exists to prohibit the use of articaine according to the current guidelines listed in the summary of product characteristics" [15]. "All local anesthetics may cause nerve injury (they are neurotoxins). The occurrence of sensory impairment is apparently slightly more frequent following use of articaine and prilocaine. However, considering the number of patients treated, sensory impairments rarely occur. For example, the incidence of sensory impairment following the use of articaine is estimated to be 1 case in 4.6 million treated patients" $[2,15]$. Furthermore, they reported that there are different incidents that can result in a nerve injury: mechanical injury due to needle trauma, direct drug toxicity or neural ischemia for example [15]. The Danish Medicines Agency followed up with this study in October 2011 (117/43) [16]. Their database of side effects comprised 160 reports of adverse reactions related to articaine between 20012005 , most of which concerning nerve damage [16]. However, since 2005 they have observed a drop in the number of new adverse reaction reports. For 2011, up until the first of October they only received 2 reports of possible sensory impairment [16]. This drop in the number of adverse effects can be explained by two phenomena: the Weber Effect and the effect of publicity on drug prescription and usage [2]. Both phenomena will be clarified later.

Pogrel also wrote some interesting papers about articaine over the years [17-21]. In a 2007 paper, Pogrel investigated 57 nonsurgical cases of paresthesia following local anesthetic administration from 2003 to 2005 [16,17]. His update on this paper in 2012 reported on an additional 41 cases from 2006 to 2011 [18]. In both reviews, Pogrel compared the percentage of the market share of the local anesthetic to the proportion of the incidences of paresthesia reports $[17,18]$. Articaine had a ratio of 1.19 in 2007 and 0.98 in 2012 [17,18]. Lidocaine did 
I Table 5. Reports of paresthesia following local anesthesia with the most common local anesthetics.

\begin{tabular}{|l|c|c|}
\hline & $\begin{array}{c}\text { Cases of } \\
\text { paresthesia }\end{array}$ & All ADRs \\
\hline Lidocaine & 247 & 7,720 \\
\hline Bupivacaine & 99 & 2,843 \\
\hline Articaine & 85 & 254 \\
\hline $\begin{array}{l}\text { Combinations of } \\
\text { local anesthesia }\end{array}$ & 45 & 2,687 \\
\hline Prilocaine & 30 & 396 \\
\hline Other & 67 & 4,647 \\
\hline Total & 573 & 18,574 \\
\hline
\end{tabular}

ADR:Adverse drug reactions

Piccinni C, Gissi DB, Gabusi A, Montebugnoli L, Poluzzi E. Paraesthesia after Local Anaesthetics: An Analysis of Reports to the FDA Adverse Event Reporting System. Basic and Clinical Pharmacology and Toxicology. 2015; Table 2

better than expected an only had a ratio of 0.64 in 2007 and 0.5 in 2012 [18]. The results are shown in table 3 (see Table 3 ) $[2,17,18]$. Following these results, Pogrel concluded that there is no disproportionate nerve involvement for articaine [22]. Prilocaine, however, does show a higher incidence (ratio 4.96 and 2.2 in 2007 and 2012 respectively) [22]. One of the points of criticism noted in this paper is that in the reports to outside agencies there is no mentioning whether the paresthesia was transient or permanent (as most of the paresthesias eventually recover) [23]. The Australian regulatory body issued a warning statement against articaine as well following a 2011 paper by Kingon discussing 5 case reports of paresthesia following local anesthetic administration [22]. However, in 2 of these cases, the only thing the patient experienced was an 'electric shock' with the injection [22]. Garisto conducted research in the United States in July 2010 with data gathered from the US Food and Drug Administration (FDA) Adverse Event Reporting System (AERS) between 1997 and 2008 [23]. From the 248 cases, of which $94.5 \%$ happened as a result of an IANB, there was as much as $89 \%$ that exclusively involved the lingual nerve [23]. Of these 248 cases, 108 resolved in a time period between 1 to 736 days [23]. In this study Garisto compared the incidences with the paper of Haas and Lennon (1995): It appears the difference in incidence is more than a tenfold (see Table 4) [13,24]. It is noteworthy that the FDA website for AERS warns that the AERS data has limitations: Reports do not require to prove a causal relationship, reports do not always contain enough detail and not all adverse events are reported [24]. Therefore, they state that AERS cannot be used to calculate incidences for the US population [24]. Another study analyzed the data of the AERS in the United States from 2005-2011.573 cases of paresthesia were identified out of the 18,574 reports [25]. Table 5 gives an overview of the reports for the most common anesthetics (see Table 5).

\subsection{Unclarities}

There are numerous comments or thoughts to be made about the controversy about paresthesia and
Iable 6. Lingual nerve involvement in reported cases of paresthesia.

\begin{tabular}{|c|c|c|c|}
\hline Authors & Country & Year & $\begin{array}{c}\text { Lingual } \\
\text { Nerve } \\
\text { Involvement } \\
\text { (\%) }\end{array}$ \\
\hline $\begin{array}{c}\text { Haas and } \\
\text { Lennon }\end{array}$ & Canada & 1995 & 70.6 \\
\hline $\begin{array}{c}\text { Hillerup and } \\
\text { Jensen }^{15}\end{array}$ & Denmark & 2006 & 77.0 \\
\hline Garisto et al. $^{24}$ & United States & 2010 & 92.7 \\
\hline Kingon et al. $^{23}$ & Australia & 2011 & 80.0 \\
\hline
\end{tabular}

Malamed SF. Articaine 30years later. Oral Health. 2016; Table 8

about the studies performed. What is the rationale behind the fact that the vast majority of paresthesias occurs after an IANB? Less than $5 \%$ of the cases involve the maxilla, while roughly half of the dental work is in the maxilla [2]. Why are these cases of paresthesia rather specific to the use of an IANB and not with alternative nerve blocks (like GowGates) [2]. Why are there no similar reported toxicity cases with articaine use in the other branches of medicine (plastic surgery, dermatology, ...) [3]. Some elements concerning the hypothesis of the neurotoxicity as the cause of the cases of paresthesia remain unexplained. As seen in the previous papers the vast majority of cases of paresthesia involved the lingual nerve, in the Garisto paper even 89\% involved exclusively the lingual nerve (see Table 6) $[2,13,14,22,23]$. If neurotoxicity caused paresthesia we would expect the inferior alveolar nerve to be involved much more commonly. Opening the mouth to deposit the cartridge could stretch out the lingual nerve, preventing it from being pushed away by the needle and being damaged [2]. In another paper, he explained this discrepancy could be partially explained by the fact that the lingual nerve only consists of one to three fascicles, while the IAN consists of five to seven fascicles [21]. The claim of a possible higher intrinsic toxicity of articaine $4 \%$ compared to lidocaine $2 \%$, which could possibly explain a higher incidence of paresthesia, was not supported in in-vitro investigations [26]. While some remain believing in the intrinsic higher neurotoxicity of the $4 \%$ anesthetics, others believe there are factors usually involved to cause the paresthesia (primarily mechanical trauma) [1]. There are a lot of different ways nerve paresthesia could be explained: Trauma by contact of the nerve sheath with the needle, hemorrhage into or around the neural sheath as the pressure on the nerve will increase, edema following surgical procedures[1]. Keep in mind that one does not exclude the other. Next, focus will be on the Weber Effect and the effect of publicity. The Weber Effect is an epidemiological event that constitutes a rise in reporting of adverse events after its regulatory approval, with a peak at the end of its second year 


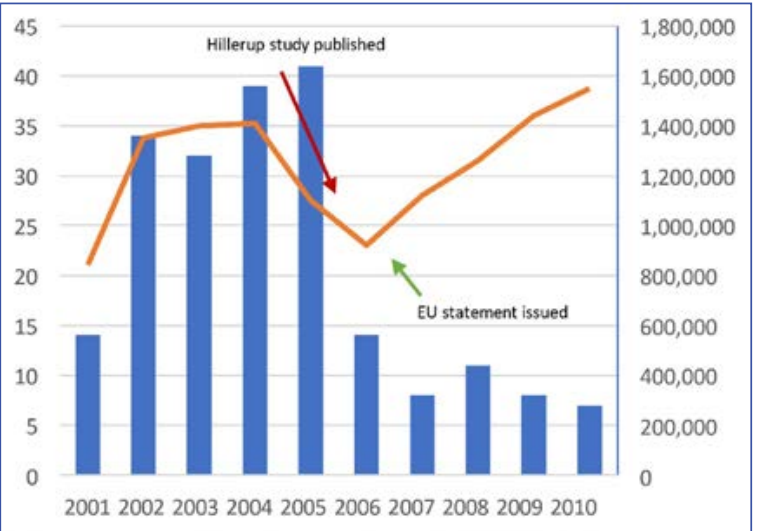

Figure 1. Articaine use and reports of paresthesia (Denmark).

Malamed SF. Handbook of Local Anesthesia. 7thed.St Louis:Mosby;2019, Figure 20.9

(see Fig. 1) [1,2]. Afterward, the reports steadily decline while prescribing rates keep rising steadily [2]. This is a replicable and verified phenomenon [27]. Publicity (whether positive or negative) affects how much drugs are used and prescribed [2]. Implemented on this debate, we conclude that indeed the use of articaine decreased after the paper of Hillerup and the recommendation of the Danish Dental Association [2]. After the EU report explaining there was no significant evidence, the use increased again [2]. Another potential confounder might be the age of the dentist, as more numerous younger, inexperienced dentists use articaine as an anesthetic [26]. The last remark is the inconsistency of the reported risks on paresthesia. As already mentioned, the variation between the reported risks is tremendous, pleading there must be some kind of bias. In his 2000 paper, Pogrel estimated the risk of permanent nerve damage following an IANB at 1 in 26,762 injections [19]. Therefore, he stated that a dentist would reasonably encounter at least one case in their career [19]. For a risk of 1 in 785,000 as mentioned in the Ontario paper however, this would mean a practitioner would encounter a paresthesia once every 436 years (averaging 1,800 injections every year) [28]. Another overall incidence reported is $1: 13,800,970$ in the US [2]. To put these risks into perspective: the risk of being struck by lightning in a given year in the US is between 1 in 328,000 and 1 in 700,000 [1].

\subsection{Conclusion}

The studies reporting an increased risk of paresthesia contain a lot of bias: The total duration of paresthesia, the injection technique, the size of the needle and even the anesthetic used (in 30\% of the incidents reported) are examples of data that are not always documented in these papers [28]. A 2011 review by Yapp highlights the flaws in studies concerning articaine: All studies reporting an increased risk contain bias in data recruitment and are retrospective [4]. They are not suitable for a strong recommendation [4]. He concluded that "although there may be controversy regarding its safety and advantages in comparison to other local anesthetics, there is no conclusive evidence demonstrating neurotoxicity or significantly superior anesthetic properties of articaine for dental procedures" [4]. Van der Sleen evaluated 1000 patients receiving an IANB, and concluded that no long-term injury will be caused as long as the mandibular nerve is not manipulated [29]. When applying a local anesthetic would result in paresthesia, these are only temporary and the cause remains unknown [29]. The most common cause of nerve injury remains mechanical trauma like surgery or third molar extractions.

Malamed makes the following recommendation: For the administration of an IANB you can continue to use articaine $4 \%$ with epinephrine $1: 100,000$ or $1: 200,000$, provided you use the correct injection techniques [2]. If, however, the practitioner is not convinced by the absence of scientific evidence or still concerned, an alternative could be to use lidocaine $2 \%$ with epinephrine 1:100,000 followed by infiltration anesthesia with articaine in the desired area to improve effectiveness [2].

\section{DISCUSSION}

In the early days of the drug, there were a lot of anecdotal claims that articaine would function faster and better than other anesthetics. Different metaanalyses confirmed that the safety profile of articaine is similar to that of lidocaine $[9,10]$. In certain clinical situations, articaine does have a significant advantage over lidocaine (mainly for infiltration anesthesia in the posterior mandibula) $[4,11,12]$. However, there is no convincing evidence to suggest that articaine has an overall superiority in efficacy over lidocaine. In 1995 a retrospective study about paresthesia occurrence after the administration of local anesthetics started a controversial debate whether or not articaine causes more paresthesias than lidocaine [11]. In the following years, numerous papers were published, and different recommendations were sent out by different regulatory bodies. All these reports on the alleged higher incidence by articaine show contradictory results, widely varying incidences, and incomplete or biased data. Malamed, well-known in matters related to local anesthesia and a proponent of articaine, wrote an interesting overview of the subject $[4,11,12]$. Whether negative or positive, most of the time one single author is proclaiming his/her own beliefs without high-quality clinical evidence like a randomized controlled trial or a proper meta-analysis to back it up. Because of the rarity of the complication, an RCT would require too large of a sample size. In 2006 the European Pharmacovigilance System concluded there was no scientific or clinical evidence of a greater risk associated with articaine after examining all available clinical data from the Septodont database [2]. The Danish authorities confirmed these conclusions after reevaluation in 2012 [2]. Up until now, 
there is no conclusive evidence that articaine would cause a larger number of paresthesias in proportion to its market share [2].

\section{CONCLUSION}

Investigations on the superiority of articaine showed an advantage over lidocaine in certain situations (like infiltration anesthesia in the posterior mandible). There is insufficient evidence to state that articaine has an overall superiority to lidocaine. Due to the lack of conclusive evidence, the choice of local anesthetic should be purely based on the practitioner's experience and personal preference.

Concerning the topic of paresthesia, there exists no scientific evidence proving the alleged higher risk of articaine on paresthesia. The available research on the matter predominantly comprises the convictions of one single author, whether positive or negative, without high-quality evidence. The main causal factor for paresthesia is still mechanical violation during

\section{REFERENCES}

1. Malamed SF. Handbook of local anesthesia . Seventh edition. St. Louis, MO: Elsevier Inc; 2020.

2. Malamed SF. Articaine 30 years later. Oral Health. [Internet] 2016. [Full text links]

3.Snoeck M. Articaine: a review of its use for local and regional anesthesia. Local Reg Anesth. 2012;5:23-33.

[Full text links] [CrossRef] [PubMed] Google Scholar Scopus

4.Yapp KE, Hopcraft MS, Parashos P. Articaine: a review of the literature. Br Dent J. 2011;210(7):323-329.

[Full text link] [CrossRef] [PubMed] Google Scholar

5.Oertel R, Richter $\mathrm{K}$, Weile $\mathrm{K}$, et al. A simple method for the determination of articaine and its metabolite articainic acid in dentistry: Application to a comparison of articaine and lidocaine concentrations in alveolus blood. Methods Find Exp Clin Pharmacol. 1993;15(8):541-547.

[PubMed] Google Scholar Scopus

6. Bennett CR. Monheim's local anesthesia and pain control in dental practice, 7th edition. St. Louis, MO: CV Mosby; 1984

7.Godzieba A, SmektałaT, Jędrzejewski M,Sporniak-TutakK.Clinical assessment of the safe use local anaesthesia with vasoconstrictor agents in cardiovascular compromised patients: a systematic review.MedSciMonit. 2014:20:393-398. doi:10.12659/MSM.889984 [Full text links] [PubMed] Google Scholar Scopus

8. Robertson D, Nusstein J, Reader A, et al. The anesthetic efficacy of articaine in buccal infiltration of mandibular posterior teeth. Am Dent Assoc. 2007 Aug;138(8):1104-1112;

[Full text link] [PubMed] Google Scholar Scopus

9. Meechan JG, Ledvinka JIM. Pulpal anaesthesia for mandibular central incisor teeth: A comparison of infiltration and intraligamentary injections. Int Endod J. 2002;35(7):629-634. [Full text link] [CrossRef] [PubMed] Google Scholar Scopus

10. Kanaa MD, Whitworth JM, Corbett IP, Meechan JG. Articaine buccal infiltration enhances the effectiveness of lidocaine inferior alveolar nerve block. Int Endod J. 2009;42(3):238-246. [Full text link] [CrossRef] [PubMed] Google Scholar Scopus

11. Katyal V. The efficacy and safety of articaine versus lignocaine in dental treatments: A meta-analysis. J Dent. 2010;38(4):307-317. [Full text link] [CrossRef] [PubMed] Google Scholar Scopus

12. Paxton K, Thome DE. Efficacy of articaine formulations: quantitative reviews. Dent Clin North Am. 2010;54(4):643-653.

[Full text link] [CrossRef] [PubMed] Google Scholar Scopus

13. Haas DA, Lennon D. A 21 year retrospective study of reports of paresthesia following local anesthetic administration. J Can Dent Assoc. 1995;61(4):319-330.

[PubMed] Google Scholar Scopus

14. Hillerup $S$, Jensen R. Nerve injury caused by mandibular block analgesia. Int J Oral Maxillofac Surg. 2006;35(5):437-443.

[Full text link] [CrossRef] [PubMed] Google Scholar Scopus

15. Stenver DI, Case number: 3200-1367, Adverse effects from surgery or tooth extractions. The lingual nerve is most frequently affected rather than the inferior alveolar nerve due to its anatomy. It should be kept in mind that a sensory disturbance after local anesthetic use in non-surgical cases still remains an extremely rare event.

\section{CONFLICT OF INTEREST}

The authors declare no conflict of interest.

\section{FUNDING}

This article did not require funding.

\section{ACKNOWLEDGMENTS}

This study was conducted as a master thesis to acquire the degree of master in medicine at the Catholic University of Leuven. anaesthetics used in relation with dental care with a special focus on anaesthetics containing articaine. Pharmacovigilance Working Party of the European Union. 20 October, 2006.

16. Danish Medicines Agency (Laegemiddel Styrelsen), Report 25 October 2011

17. Pogrel MA. Permanent nerve damage from inferior alveolar nerve blocks - an update to include articaine. J Calif Dent Assoc. 2007:35(4):271-273.

[Full text link] [PubMed] Google Scholar Scopus

18.PogrelMA.Permanentnervedamagefrominferioralveolarnerve blocks: a current update. J Calif Dent Assoc. 2012;40(10):795-797. [Full text link] [CrossRef] [PubMed] Google Scholar Scopus

19. Pogrel MA, Thamby S. Permanent nerve involvement resulting from inferior alveolar nerve blocks [published correction appears in J Am Dent Assoc. 2000;131(10):1418]. J Am Dent Assoc. 2000;131(7):901-907.

[Full text link] [PubMed] Google Scholar Scopus

20. Pogrel MA, Thamby S. The etiology of altered sensation in the inferior alveolar, lingual, and mental nerves as a result of dental treatment. J Calif Dent Assoc. 1999;27(7):531-538. [PubMed] Google Scholar Scopus

21. Pogrel MA, Schmidt BL, Sambajon V, Jordan RCK. Lingual nerve damage due to inferior alveolar nerve blocks: a possible explanation. J Am Dent Assoc. 2003;134(2):195-199. [Full text link] [CrossRef] [PubMed] Google Scholar Scopus

22. Kingon A, Sambrook P, Goss A. Higher concentration local anaesthetics causing prolonged anaesthesia. Do they? A literature review and case reports. Aust Dent J. 2011;56(4):348-351.

[Full text link] [CrossRef] [PubMed] Google Scholar

23. Garisto GA, Gaffen AS, Lawrence HP, et al. Occurrence of paresthesia after dental local anesthetic administration in the United States [published correction appears in J Am Dent Assoc 2010;141(8):944]. J Am Dent Assoc. 2010;141(7):836-844.

[Full text link] [CrossRef] [PubMed] Google Scholar Scopus

24. U.S. Food and Drug Administration Center for Drug Evaluation and Research, Office of Post-Marketing Drug Risk Assessment. Revised 9 January 2009. http://www.fda.gov/Drugs/ GuidanceComplianceRegulatorylnformation/Surveillance/ AdverseDrugEffects/default.htm.

25. Piccinni C, Gissi DB, Gabusi A, et al. Paraesthesia after local anaesthetics: an analysis of reports to the FDA Adverse Event Reporting System. Basic Clin Pharmacol Toxicol. 2015;117(1):52-56. [Full text link] [CrossRef] [PubMed] Google Scholar Scopus 26. Hopman AJG, Baart JA, Brand HS. Articaine and neurotoxicity - a review. Br Dent J. 2017;223(7):501-506. [Full text link] [CrossRef] [PubMed] Google Scholar Scopus 27. Hartnell NR, Wilson JP. Replication of the Weber effect using postmarketing adverse event reports voluntarily submitted to the United States Food and Drug Administration. Pharmacotherapy. 


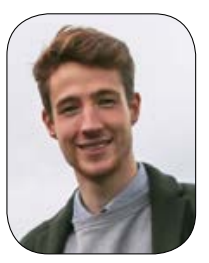

Nicolas De Ridder (DOB: 28th of May, 1996) obtained his bachelor's degree in Medicine at the Catholic University of Leuven, Belgium (magna cum laude). He is currently in his final year of master in Medicine, expected to graduate in July 2020. He has acquired experience in internships in the department of Stomatology, Oral and Maxillofacial surgery under the supervision of Professor Constantinus Politis at UZ Leuven.

\section{Ouestions}

\section{What is the most common cause of overdose reactions or complications in dental treatment with local anesthetics?}

$\square$ a. Using an excessive total dose of the drug;

b. Not complying with the listed contraindications;

ac. Use in children;

ad. Use in cardiovascular compromised patients.

\section{What is true about the efficacy of articaine compared to lidocaine?}

$\square$ a. Articaine is overall the superior local anesthetic;

b. The efficacy of articaine is similar to that of lidocaine, with an advantage in certain clinical situations;

ac. Articaine is an inferior local anesthetic compared to lidocaine;

$\square \mathrm{d}$. Articaine is a better local anesthetic than lidocaine, but it is not worth the benefit because of its higher risks.

\section{Which of the following statements concerning the pharmacological properties about articaine is not true?}

$\square$ a. Articaine has a shorter elimintation half-life than most other local anesthetics;

b. Articaine has a thiophene ring ensuring greater lipid solubility;

口c. Articaine contains an ester-linkage that can be hydrolyzed by plasma-esterase, making it a hybrid molecule;

$\square$ d. Articaine has a low degree of protein-binding, just as most other local anesthetics.

\section{The incidence of paresthesia for articaine is:}

$\square$ a. Significantly lower than lidocaine;

b. In relation to its market share;

ac. Higher than prilocaine;

$\square$ d. Higher than its market share. 